\title{
Distribución y segregación espacial de los centros comerciales en Cancún, Quintana Roo (1979-2019)
} DISTRIBUTION AND SPATIAL SEGREGATION OF SHOPPING CENTERS IN CANCUN, QUINTANA ROO (1979-2019)

DISTRIBUIÇÃO E SEGREGAÇÃO ESPACIAL DOS CENTROS COMERCIAIS

EM CANCUN, QUINTANA ROO (1979-2019)

Edgar Elías Fonseca Chicho ${ }^{1}$

Rosalía Chávez Alvarado ${ }^{2}$

José Manuel Camacho Sanabria ${ }^{3}$

\section{Resumen}

El objetivo de este trabajo es analizar la distribución de los centros comerciales y su consecuente segregación en Cancún, Quintana Roo, ciudad que en las últimas décadas ha registrado un incremento en la construcción de estos inmuebles. La metodología desarrolló en dos fases: la primera, mediante el levantamiento en campo de una cédula que integra los centros comerciales por tipo de tienda ancla, y la segunda, a través de la caracterización de estos inmuebles a partir de su ubicación; lo anterior derivó en cinco distribuciones que permiten comprender la segregación espacial para tres zonas de la ciudad en un periodo que va del año 1979 (primer centro comercial) hasta el año 2019. Los resultados constatan preferencias espaciales que constituyeron un territorio

\footnotetext{
Maestro en Ciencias y Artes para el Diseño (área de investigación y gestión territorial), Universidad Autónoma Metropolitana (UAM). Maestro en Psicología Social, Benemérita Universidad Autónoma de Puebla (BUAP). Candidato a doctor en Geografía, Universidad de Quintana Roo (UQROO). Correo: eliasfonseca@comunidad.unam.mx.

2 Doctora en Filosofía con orientación en Asuntos Urbanos, Universidad Autónoma de Nuevo León (UANL). Adscrita como Cátedra Conacyt, Universidad de Quintana Roo (UQROO), e investigadora del Sistema Nacional de Investigadores (SNI-Conacyt).Correo: rosaliadf@gmail.com.

3 Doctor en Ciencias Ambientales, Universidad Autónoma del Estado de México (UAEM). Adscrito como Cátedra Conacyt en la Universidad de Quintana Roo (UQROO), e investigador del Sistema Nacional de Investigadores (SNI-Conacyt).Correo: jmanuelcs@live.com.mx.
} 
con una perspectiva neoliberal que prioriza la satisfacción de necesidades comerciales de usuarios temporales, ubicando los mejores centros en lugares exclusivos y ajustados para la población flotante que visita la zona turística y para los ciudadanos que habitan las áreas con mejor calidad de vida. Se concluye que la distribución de los centros comerciales ha colaborado en la agudización del territorio segregado que caracteriza a la ciudad de Cancún.

Palabras clave: centros comerciales, distribución espacial, estructura urbana, segregación espacial, tiendas departamentales, tiendas de autoservicios.

\section{Abstract}

This paper aims to analyze the distribution of shopping malls and their consequent segregation in Cancun, Quintana Roo, which has seen an increase in the construction of these properties in recent decades. The method is carried out in two phases: the first, a field survey that groups shopping centers by type of anchor store and the second, the characterization of these properties based on their location. This resulted in five distributions that allow understanding the spatial segregation for three areas of the city in the period between 1979 (first shopping center) and 2019. The results confirm spatial preferences for a territory with a neoliberal perspective that prioritizes the satisfaction of commercial needs of walk-in customers, locating the best centers in exclusive places for the floating population that visits the tourist area and the citizens who inhabit the neighborhoods with the highest quality of life. It is concluded that the distribution of shopping centers has helped to exacerbate the segregated territory that characterizes Cancun.

Keywords: Shopping centers, spatial distribution, urban structure, spatial segregation, department stores, self-service stores.

\section{Resumo}

O objetivo deste trabalho é analisar a distribuição dos centros comerciais e sua consequente segregação em Cancun, Quintana Roo, cidade que nas últimas décadas viu um aumento na construção dessas propriedades. A metodologia foi realizada em duas fases: a primeira, através da pesquisa de campo de um certificado que integra os centros comerciais por tipo de âncora, e a segunda, através da caracterização desstes inmóveis com base em sua localização; o mencionado acima levou a cinco distribuições que possibilitam entender a segregação espacial em três áreas da cidade, em um período que vai de 1979 (primeiro centro comercial) até o ano 2019. Os resultados confirmam preferências espaciais que constituíram um território com uma perspectiva neoliberal que prioriza a satisfação das necessidades comerciais dos usuários temporários, localizando os melhores centros em locais exclusivos e adequados para a população flutuante que visita a área turística e para os cidadãos que habitam as áreas com maior qualidade de vida. Conclui-se que a distribuição dos centros comerciais têm contribuido à exacerbação do território segregado que caracteriza a cidade de Cancun.

Palavras-chave: centros comerciais, distribuição espacial, estrutura urbana, segregação espacial, lojas de departamento, lojas de autoatendimento. 


\section{Introducción}

A partir del año 2017 han surgido diversas publicaciones donde se expone el aparente declive ${ }^{4}$ de los centros comerciales en diferentes países desarrollados, principalmente en Estados Unidos (lugar donde se originaron los malls). Paradójicamente, en los países emergentes parecen estar en pleno ascenso, principalmente los de América Latina y el Caribe, pues, de acuerdo a la información recabada en la Tabla 1, México es actualmente el país con más centros comerciales en el continente, con un ritmo de crecimiento de diez construcciones anuales en la última década, y se espera que se duplique a veinte establecimientos anuales durante los próximos diez años.

Entre las causas mencionadas por los autores se rescatan las siguientes: el boom del comercio online, las instalaciones obsoletas y la sobreoferta de centros comerciales.

TABLA 1. CENTROS COMERCIALES EN PAÍSES LATINOS

\begin{tabular}{|c|c|c|c|}
\hline País* & Año 2015 & Año 2017 & Proyección al año 2025 \\
\hline México & 584 & 604 & 800 \\
\hline Brasil & 511 & 525 & 700 \\
\hline Colombia & 196 & 211 & 339 \\
\hline Argentina & 114 & 132 & 320 \\
\hline Chile & 79 & 92 & 178 \\
\hline Perú & 71 & 75 & 90 \\
\hline \multicolumn{4}{|c|}{$\begin{array}{l}\text { Fuente: elaboración propia con base en datos del International Council of Shopping Centers (ICSC, 2016), United Business Media (UBM, 2015)**, Olguín (2011) } \\
\text { Pradilla (2017) y Treviño (2017). }\end{array}$} \\
\hline \multicolumn{4}{|c|}{ * La tabla solo contiene los países con mayor dinamismo en la construcción de centros comerciales en América Latina. } \\
\hline \multicolumn{4}{|c|}{$\begin{array}{l}\text { ** UBM cambió de nombre en septiembre de } 2019 \text { y actualmente es Informa Markets Latam. La nueva plataforma digital está disponible en www.informamarke } \\
\text { com. }\end{array}$} \\
\hline
\end{tabular}

Investigadores como Ramírez Kuri (1993, 1998), López (1999), Vázquez (2000), Lulle y Paquette (2007), Pradilla (2017) y Gasca-Zamora (2017) coinciden al mencionar que a nivel nacional los centros comerciales han copiado los patrones urbanos estadounidenses siguiendo la tendencia de construcción y la creación de suburbios, donde la proliferación de los centros comerciales en el país fue mayor en la Ciudad de México (antes Distrito Federal) y su área metropolitana en comparación con otros estados. Sin embargo, en las últimas décadas otras ciudades han tomado importancia para 
los inversionistas de estos inmuebles comerciales y una de ellas es la ciudad de Cancún, perteneciente al estado de Quintana Roo.

El auge de los centros comerciales en Cancún (originado por ser núcleo turístico mundial de sol y playa) se puede ver en la Tabla 2 frente a la construcción de estos inmuebles en otras ciudades mexicanas. Aquí sobresalen los crecimientos para Guadalajara y Cancún en la proyección a 2025, dado que Guadalajara estaría desplazando a Monterrey del tercer al cuarto lugar y Cancún subiría al quinto lugar nacional, por encima de Puebla.

TABLA 2. CENTROS COMERCIALES EN LAS PRINCIPALES CIUDADES MEXICANAS

\begin{tabular}{|c|c|c|c|c|}
\hline Ciudad & Año 2011 & Año 2015 & Año 2017 & $\begin{array}{l}\text { Proyección } \\
\text { año } 2025\end{array}$ \\
\hline Ciudad de México & 163 & 196 & 208 & 276 \\
\hline Edo. Méx.* & 58 & 80 & 87 & 130 \\
\hline Monterrey & 43 & 50 & 53 & 67 \\
\hline Guadalajara & 30 & 45 & 51 & 85 \\
\hline Puebla & 20 & 24 & 26 & 35 \\
\hline Cancún & 15 & 20 & 26 & 50 \\
\hline
\end{tabular}

Fuente: elaboración propia con base en datos del ICSC (2016), UBM (2015), Olguín (2011), Pradilla (2017) y Treviño (2017).

*Comprende solo los municipios pertenecientes a la Zona Metropolitana del Valle de México.

El punto crucial de la situación es que de seguir estas tendencias se espera una saturación de centros comerciales en Cancún dado que la tasa de crecimiento a 2025 se duplicaría, es decir, se tendrían tres centros comerciales anuales y se alcanzarían los 50 centros en actividad; sorprendentemente, estaría emulando la dinámica de crecimiento de las cuatro principales ciudades mexicanas ${ }^{5}$. Este panorama se vuelve alarmante, ya que con tal proliferación se esperaría mayor segregación espacial en la ciudad. Lo anterior se puede cotejar en la Tabla 3, que muestra el crecimiento constante de la superficie total construida y su relación con el total poblacional.

Según el Consejo Nacional de Población (Conapo, 2012), en el sistema urbano nacional la jerarquía urbana de mayor a menor la ocupan la Ciudad de México-Estado de México, Guadalajara, Monterrey y Puebla-Tlaxcala. 
TABLA 3. SUPERFICIE TOTAL DE CENTROS COMERCIALES POR HABITANTE

\begin{tabular}{cccc}
\hline Año & Población & Superficie $\left(\mathrm{m}^{2}\right)$ & $\mathrm{M}^{2} \times$ hab. \\
\hline 1980 & 37.190 & 10.500 & 0,28 \\
\hline 1982 & 70.000 & 25.000 & 0,36 \\
\hline 1990 & 176.765 & 52.000 & 0,29 \\
\hline 1995 & 297.183 & 159.000 & 0,54 \\
\hline 2000 & 419.815 & 401.500 & 0,96 \\
\hline 2005 & 526.701 & 650.500 & 1,24 \\
\hline 2010 & 661.176 & 990.500 & 1,50 \\
\hline
\end{tabular}

Fuente: Instituto de Planeación del Desarrollo Urbano (Implan, 2008), Inegi (1980, 1990, 2000, 2010, 2015) y Consejo Nacional de Población (Conapo, 2012).

La traza urbana de Cancún sería similar a un plato roto, ya que cada centro comercial activa la dinámica espacial, separa zonas habitacionales y enclava las zonas comerciales, lo que impacta en la vialidad, obliga a adaptar los recorridos urbanos y crea zonas inseguras. De acuerdo con Calderón y Orozco (2009), el modelo urbano de Cancún se ha distinguido por presentar una segregación residencial cada vez más marcada, donde se dan grandes diferencias en cuanto al tipo de alojamiento, la infraestructura y los servicios públicos disponibles, lo cual resulta ser una característica del capitalismo subdesarrollado contemporáneo. Por su parte, Castillo (2011) mencionó que esta ciudad está dividida, fragmentada y claramente segregada en términos socioespaciales, donde la mayor parte de la población de menores ingresos convive en dos realidades absolutamente diferentes y contradictorias, razón por la cual en Cancún la miseria y la exclusión conviven con el lujo y la opulencia. Respecto a este contexto, Cárdenas
(2016) asevera que Cancún es un claro ejemplo de la segregación vivida en las ciudades turísticas de sol y playa. Este fenómeno socioespacial fue evidente por las viviendas construidas para trabajadores en áreas periféricas, con infraestructura inadecuada e insuficiente, donde además se olvidaron de construir espacios públicos y áreas verdes (Sosa \& Cazal, 2015).

Ante lo anterior, cabe mencionar a Medina (1998), López (2006) y Salcedo-Hansen (2003), quienes coinciden en que los centros comerciales refuerzan la segregación urbana a partir de un proceso derivado de la edificación de recintos fortificados, la formación de enclaves económicos (Daltabuit, Cisneros, Vázquez \& Ruiz, 2006), la sustitución de espacios públicos, el alto índice de marginación, los asentamientos irregulares y la violencia en diferentes ámbitos. En el mismo telar se encuentran las investigaciones de autores como Ramírez Kuri (1993, 1998), López (1999), Vázquez (2000), Müller (1998), Cornejo (2006), Lulle y Paquette 
(2007), Ramírez y Pradilla (2014), Pradilla (2017) y Gasca-Zamora (2017), quienes han llegado a resultados con connotaciones principalmente negativas sobre la construcción de estos inmuebles, ya que, en su mayoría, indican que los centros comerciales inciden en el crecimiento demográfico y físico de las ciudades, impactan vialidades, cambian los usos de suelo, desplazan población y atraen población flotante dañina, fragmentan o segregan socioespacialmente, privatizan el espacio público, corrompen identidades y globalizan y homogeneizan a los ciudadanos, entre otros asuntos.

En este trabajo se analiza la distribución espacial de los centros comerciales en Cancún a partir de la inserción de estas edificaciones en la estructura urbana y la reproducción de algunas relaciones con la segregación espacial. La investigación es pertinente porque busca iniciar el debate sobre las consecuencias urbanas de los centros comerciales en Cancún y la existencia de escasa literatura al respecto. Lo anterior a partir de una acotación de 31 centros comerciales anclados ${ }^{6}$ por tiendas departamentales ${ }^{7}$, de autoservicios o supermercados, y de cadenas de cine y restaurantes, los cuales de-

6 La tienda o servicio ancla se define como aquella que es la figura simbólica de mayor atracción comercial. Al principio incluso proporcionaban un estatus social, lo cual segmentaba espacial y socialmente con su presencia. En la actua lidad, se utilizan como tiendas o servicios ancla las tiendas departamentales, como Walmart, Soriana y HEB en ciertas regiones del norte de México. Otro ejemplo de anclaje se presenta con las cadenas de cine, principalmente en zonas donde habitan personas de estratos socioeconómicos más deprimidos, donde son el sustituto de espacios públicos para su recreación.

La definición de tienda departamental se recupera de Váz quez (2000), quien refiere que son espacios comerciales que incluyen una gran diversidad de productos en un mis mo espacio donde cada mercancía se encuentra agrupada por departamentos dependiendo de su función. A diferencia de las galerías comerciales europeas, estas tiendas se protegen en su totalidad de las inclemencias del clima al ser construcciones cerradas que cuentan con pequeños aparadores que exhiben productos. El patrón de las tiendas departamentales se reprodujo en Nueva York con Lord \& Taylor, Arnold Constable y Marcy's, y en Chicago con Potter Palmer y Marshall Field's. velan la situación actual de la configuración espacial de la ciudad.

\section{Metodología}

Este trabajo se realizó a partir de una exhaustiva revisión literaria en las bases de datos de revistas indexadas cuyo tema fuera el análisis, la descripción y la comprensión de los centros comerciales en la configuración de las ciudades. Así mismo, se realizó trabajo de campo para georreferenciar y plasmar en figuras los datos de estos centros en la ciudad. El documento cubre un periodo que va desde la instauración del primer centro comercial registrado en la historia de Cancún hasta el último programado, es decir, de 1979 a 2019. El análisis de los centros comerciales hubiese sido imposible si no se hubiera realizado una acotación que definiera una muestra maleable, pues Cancún, al ser una ciudad turística y, por ende, terciarizada (de acuerdo a la producción en los sectores económicos), se compone de múltiples comercios de diferentes tamaños y giros. Por tal razón la acotación de los centros comerciales se construyó a partir de los planteamientos académicos elaborados en México, los cuales dictan que la historia de estos inmuebles comerciales comenzó con las tiendas departamentales que derivaron en la construcción de Plaza Universidad, el primer centro comercial del país reconocido como mall, localizado en la Ciudad de México.

En el trabajo de campo realizado en los meses de junio, julio y agosto de 2019 se encontraron plazas pequeñas con anclas de alcance local y centros comerciales que incluyen cines y tiendas de autoservicio rodeados de comercios medianos, los cuales podrían ser considerados como un ancla del nivel 
de las tiendas departamentales, ya que poco a poco han llamado la atención de los empresarios por ser generadores de influencia y atracción. Frente a esto, cabe recordar a Vázquez (2000), quien menciona lo siguiente: como resultado de las diferentes estrategias para atraer más personas, el concepto de centro comercial ha evolucionado y ahora el consumo se expande para mezclar actividades de esparcimiento que permitan a los usuarios no solo comprar bienes, sino también hacer uso de servicios, bancos, alimentos, cines, juegos de video, eventos culturales, discotecas o únicamente deambular o pasear por los pasillos observando a la gente, es decir, "pasar el tiempo" (Vázquez, 2000, p. 119).

Dado que este trabajo analítico es de carácter descriptivo y explicativo, se estructura en dos bloques. El primero aborda de manera general la historia de los centros comerciales en México y Cancún, lo cual se elaboró a partir de técnicas documentales y estadísticas que derivaron en una cédula levantada en campo. En el segundo bloque se muestra la distribución espacial de los centros comerciales por medio de un sistema de información geográfica (SIG); aquí se produce una síntesis de la ubicación de estos inmuebles comerciales en la estructura urbana de la ciudad donde, presumiblemente, se asocian a la segregación urbana de Cancún. Para el levantamiento de la cédula se realizaron recorridos en campo para validar la información obtenida en gabinete. Se registraron y puntualizaron las coordenadas geográficas de cada centro comercial a través de un GPS Garmin GPSMAP 60 Portable Navigator, con la finalidad de facilitar su interpretación y digitalización. Para el análisis de la distribución espacial se elaboró una zonificación que integra los sectores más representativos de Cancún; esto se construyó tomando en cuenta algunas variables del Censo de Población y Vivienda del Instituto Nacional de Estadística, Geografía e Informática (Inegi) de 2010 y los instrumentos de planificación urbana, cruzados con los datos históricos sobre el crecimiento urbano y los artículos académicos sobre la situación actual en la ciudad cancunense. Cabe destacar que se toma en consideración la propuesta de corredores terciarios planteada por Pradilla y Pino (2004), dado que el presente caso coincidió con respecto a la estructuración de ejes comerciales que se articulan en torno a la localización de cada centro comercial, principalmente sobre las vías primarias. En la Tabla 4 se pueden observar con mayor detalle cada una de las variables consideradas. 
TABLA 4. ZONIFICACIÓN PARA EL ANÁLISIS DE LA DISTRIBUCIÓN ESPACIAL

\begin{tabular}{|c|c|}
\hline Insumo & Variables \\
\hline $\begin{array}{l}\text { Bibliografía: datos históricos de creci- } \\
\text { miento urbano y artículos académicos. }\end{array}$ & $\begin{array}{l}\text { Pérez y Carrascal (2000); Calderón y Orozco (2009); Casti- } \\
\text { Ilo (2011); Sosa y Cazal (2014) y Pradilla y Pino (2004). }\end{array}$ \\
\hline \multirow{7}{*}{$\begin{array}{l}\text { Censo de Población y Vivienda (Inegi, } \\
\text { 2010), sobreposición de capas (ArcGis) e } \\
\text { instrumentos de planificación urbana. }\end{array}$} & Densidad poblacional (ha) \\
\hline & Total de viviendas particulares habitadas \\
\hline & Total de viviendas particulares de uso temporal \\
\hline & Viviendas particulares sin servicios \\
\hline & Promedio de escolaridad \\
\hline & Plan Municipal de Desarrollo del municipio de Benito Juárez (2018-2021) \\
\hline & PDU Cancún (2014-2030) \\
\hline \multicolumn{2}{|c|}{$\begin{array}{l}\text { Fuente: elaboración propia con base en Inegi (2010), Pérez y Carrascal (2000), Calderón y Orozco (2009), Castillo (2011), Sosa y Cazal (2014), Pradilla y Pino } \\
\text { (2004), Ayuntamiento de Benito Juárez (2018), Programa de Desarrollo Urbano (PDU) del Centro de Población Cancún, Municipio Benito Juárez, Quintana Roo } \\
\text { (2014-2030). }\end{array}$} \\
\hline
\end{tabular}

Finalmente es importante mencionar que las figuras que se representan a partir de la anterior zonificación consideran las variables más representativas del tiempo y el espacio en cuanto a los centros comerciales, es decir, año de inauguración, tiendas y tamaño. De esta forma se muestran las distribuciones por décadas, por sexenios presidenciales, por tipo de anclaje, por tipo de área de influencia y por tamaño de superficie.

\section{Resultados}

\subsection{Centros comerciales en México}

Los centros comerciales en América Latina y el Caribe empezaron a surgir a partir de la segunda mitad de la década de los sesenta. En México los primeros centros comerciales surgieron en la Ciudad de México a finales de la misma década y reprodujeron los modelos planteados en Estados Uni- dos. De acuerdo con los datos consultados en esta investigación y el cotejo con el estudio de campo, la historia de los centros comerciales en Cancún comienza en 1979 con la construcción de Plaza Caracol, ubicado en el corazón de la zona hotelera de acuerdo con la traza urbana de ese tiempo. Es importante destacar que el primer centro comercial de Cancún se edificó una década después de la construcción del primer centro comercial en México, sin embargo, esto es relativamente rápido si se considera que su fundación como ciudad fue ocho años antes, es decir, en 1971, cuando el Banco de México intervenía en la política del proyecto como Centros Integralmente Planeados (CIP) (Sosa \& Cazal, 2015).

El origen de los centros comerciales en México está muy ligado a los procesos de expansión de los almacenes departamentales. Ramírez Kuri (1993) plantea que las tiendas departamentales han jugado un papel relevante en el desarrollo de los centros 
comerciales como empresas en expansión que promueven la comercialización de productos nacionales e internacionales. Las tiendas departamentales son el precedente de los centros comerciales, tal y como lo afirma esta investigadora. "Los grandes almacenes pasan a formar parte del contexto económico-social de la ciudad moderna a fines del siglo XIX y principios del XX [...] por ser emporios comerciales privados y al mismo tiempo instituciones aceptadas y legitimadas por la comunidad, los grandes almacenes representan al antecedente más cercano de los centros comerciales actuales" (Ramírez Kuri, 1993, pp. 39-40).

Lo anterior coincide con Vázquez (2000), ya que afirma que los principales inversionistas en la construcción de los centros comerciales son los grandes grupos económicos dueños de las tiendas departamentales: GPH para El Palacio de Hierro, División inmobiliaria Liverpool para Liverpool y Grupo Carso para Sears. Por otro lado, se tiene una reafirmación con Gasca-Zamora (2017), pues indica que los primeros centros comerciales surgidos en la Ciudad de México fueron resultado de la asociación entre tiendas departamentales y desarrolladores inmobiliarios nacionales. Las primeras incursionaron en la construcción de estos inmuebles como estrategia para captar mayores cuotas de consumidores, promoviendo en su propio edificio la apertura de unidades complementarias de distribución de productos, servicios y entretenimiento ${ }^{8}$. Cabe destacar que, de acuerdo con el autor, estas fórmulas asociativas fueron imitadas por las grandes tiendas mexicanas de autoservicios para edificar distintas modalidades de plazas y conjuntos comerciales.

Según Gasca-Zamora (2017), este fue el principio del diseño, donde la tienda ancla departamental representaba su eje articulador.
La mayoría de los centros comerciales más reconocidos ${ }^{9}$ por la sociedad mexicana se encuentran anclados por El Palacio de Hierro, Liverpool o Sears. Estas tres tiendas departamentales tradicionalmente se han dirigido a la población de ingresos medios y altos. Según Ramírez Kuri (1993), desde sus inicios fueron edificaciones monumentales cargadas de imágenes y representaciones materializadas en una amplia gama de productos y bienes de consumo. En este sentido, respondieron a los intereses y aspiraciones de la elite social que las sostenía y, por consiguiente, los grandes almacenes se fueron consolidando también como instituciones de importancia social y cultural para la comunidad.

\subsection{Centros comerciales en Cancún}

Según datos del International Council of Shopping Centers $(\text { ICSC })^{10}$, Cancún tenía 20 centros comerciales en 2016, con un total de $448.650 \mathrm{~m}^{2}$ de área bruta arrendable. Sin embargo, en sus estadísticas consideran los centros comerciales dependiendo de su afiliación al organismo. En los últimos años las empresas de cine Cinépolis ${ }^{11}$ y Cinemex se han posicionado como anclas de centros comerciales (según la ICSC, en 2016 existían 50 salas en Cancún). En la cédula levantada se registraron nueve

Por reconocidos, entiéndase los que han sido legitimados socialmente por la población, sea o no consumidora de esos centros comerciales.

10 La mayoría de los centros comerciales del mundo se encuentran asociados al International Council of Shopping Centers (ICSC), una organización estadounidense fundada en 1957 que analiza las dinámicas de los centros comerciales haciendo constantes estudios a nivel mundial, e incluso premia anualmente a los mejores del mundo según sus categorías

11 Enrique Ibarrola (director de desarrollo inmobiliario y expansión del complejo de cines Cinépolis) mencionó que los planes de expansión apuntan a economías sudamericanas como lo están haciendo en Colombia, donde son ancla de varios centros comerciales construidos en Cali, Medellín y Bogotá. Los cines son un buen complemento de los centros comerciales, pero hay que concebirlos como una inversión a largo plazo (García, 2016). 
de 31 , es decir, la presencia de anclaje o subanclaje de cines se encuentra en el 30\% del total de los centros comerciales. Cabe destacar que también se observaron centros comerciales anclados por estas empresas acompañados de establecimientos de juegos de azar o apuestas, además de otros anclados por tiendas exclusivas localizados principalmente en la zona turística de Cancún.

Se destaca la existencia de múltiples plazas comerciales pequeñas con anclas muy localizadas, de impacto y atracción a nivel de colonia, dado que Cancún, al ser una ciudad dedicada en su mayoría al comercio y los servicios complementarios al turismo de sol y playa, contiene múltiples inmuebles comerciales de este tipo, las cuales se van acrecentando y especializando conforme se acercan a la zona hotelera, creando corredores de comercio y servicio específicamente en las vías que llevan o intersectan en el boulevard Kukulkán, la carretera Cancún-Tulum, la avenida Andrés Quintana Roo y la avenida Nichupté. Por otro lado, es importante anotar que las tiendas de autoservicio ${ }^{12}$ han ido ganado terreno, ya que en investigaciones elaboradas por la ICSC (2016) está aumentando el porcentaje de construcción de este tipo de tiendas acompañadas de un conglomerado de pequeños negocios. Según este organismo internacional, cuando una tienda ancla busca especializarse se le denomina category killer, ya que buscan introducir un producto específico y una imagen para el centro comercial. Por ejemplo, anteriormente estas tiendas eran consideradas como supermercados, pero en la actualidad se presentan como un pilar especializado muy parecido a una tienda departamental, dado que en varios centros comerciales que anclan se incluyen restaurantes y entretenimientos.

12 Algunos organismos encargados del ordenamiento comercial como el ICSC las denominan "plazas comerciales".

Vol. 25 N. ${ }^{\circ} 1$

enero - junio de 2020

pp. $120-142$

\subsection{Cédula de centros comerciales al 2019}

Es importante mencionar que en los instrumentos de planificación urbana de Cancún existe una referencia directa a los centros comerciales en el apartado de "Comercio y abasto" del PDU 2014-2030:

En el comercio privado, destaca la presencia de centros comerciales de gran escala. Estos han tenido una aceptación notable por parte de los habitantes y por lo tanto se ha incrementado su oferta en los últimos años. La mezcla de usos en ellos es cada vez más frecuente, logrando satisfacer actividades de comercio, abasto y recreación, entre otras. Los principales centros comerciales son Plaza Las Américas, Plaza Outlet y Paseo Cancún. La Zona Hotelera también cuenta con infraestructura relevante de centros comerciales como la llamada Plaza Kukulkán y La Isla (p. 105).

Como se puede observar, el PDU 2014-2030 solo menciona cinco centros comerciales estipulados como de "gran escala". Sin embargo, en el trabajo de campo se encontraron 31 centros comerciales, incluyendo los mencionados por el programa de desarrollo. Los resultados de la composición de la cédula se presentan a continuación por medio de una matriz que considera año de apertura, nombre del inmueble y tiendas ancla (Tabla 5). 
TABLA 5. CÉDULA DE CENTROS COMERCIALES EN CANCÚN AL 2019

\begin{tabular}{|c|c|c|c|c|c|c|c|}
\hline Núm. & Año* & $\begin{array}{l}\text { Centro o plaza } \\
\text { comercial }\end{array}$ & Anclas** & Núm. & Año* & $\begin{array}{l}\text { Centro o plaza } \\
\text { comercial }\end{array}$ & Anclas** \\
\hline 1 & 1979 & Plaza Caracol & $\begin{array}{l}\text { Benetton, Pelletier, Casa } \\
\text { Rolandi, Consulados } \\
\text { honorarios de EE. UU., } \\
\text { Canadá y Argentina }\end{array}$ & 17 & 2008 & Pabellón Cumbres & $\begin{array}{l}\text { Sams's Club, } \\
\text { Superama }\end{array}$ \\
\hline 2 & $\begin{array}{l}1986 \\
1994 y \\
2012\end{array}$ & $\begin{array}{l}\text { Las Tiendas de } \\
\text { Cancún (Pla- } \\
\text { za Cancún) }\end{array}$ & $\begin{array}{l}\text { Almacenes Blanco (1986- } \\
\text { 1992), Gigante (1993), } \\
\text { Mercado Soriana (2012) }\end{array}$ & 18 & 2008 & Plaza Mundo Maya & Chedraui \\
\hline 3 & 1988 & Flamingo Mall*** & $\begin{array}{l}\text { Pat'O Brien's, Jimmy Bu- } \\
\text { ffetts's, Planet Hollywood }\end{array}$ & 19 & 2009 & Plaza Talleres & $\begin{array}{l}\text { Mercado Soriana, } \\
\text { Bodega Aurrera }\end{array}$ \\
\hline 4 & $\begin{array}{c}1992 \\
2014 y \\
2018\end{array}$ & Plaza Kukulkan & $\begin{array}{l}\text { Soriana Súper (2014) } \\
\text { Espacio Latino (2018) }\end{array}$ & 20 & 2010 & Malecón Las Américas & Liverpool, Chapur \\
\hline 5 & $\begin{array}{l}1995 y \\
2015\end{array}$ & Plaza Xcaret & Walmart, Sam's & 21 & 2012 & Multiplaza Villas del Mar & Chedraui \\
\hline 6 & 1997 & Forum by the Sea & $\begin{array}{l}\text { Hard Rock, Rainforest, } \\
\text { Carlos'n Charlie's, Chili's }\end{array}$ & 22 & 2013 & Multiplaza Chac Mool & Chedraui \\
\hline 7 & $\begin{array}{l}1998 y \\
2005\end{array}$ & $\begin{array}{l}\text { Centro comer- } \\
\text { cial Las Améri- } \\
\text { cas Cancún }\end{array}$ & Sears, Liverpool, Chedraui & 23 & 2013 & Mi Plaza Héroes & $\begin{array}{l}\text { Mercado Soria- } \\
\text { na, Cinemex }\end{array}$ \\
\hline 8 & $\begin{array}{l}1999 y \\
2012\end{array}$ & $\begin{array}{l}\text { La Isla Shop- } \\
\text { ping Village }\end{array}$ & $\begin{array}{l}\text { Palacio de Hierro (2010) } \\
\text { Liverpool (2012) }\end{array}$ & 24 & 2013 & Multiplaza Lak'in & Chedraui \\
\hline 9 & 1999 & Plaza Yaxchilán & $\begin{array}{l}\text { Costco, Mega Comercial } \\
\text { Mexicana (Soriana 2018) }\end{array}$ & 25 & 2014 & Plaza Nahil & Bodega Aurrera \\
\hline 10 & 2001 & Multiplaza La Luna & Soriana & 26 & 2015 & Plaza La Roca & $\begin{array}{l}\text { Cinemex, } \\
\text { Wings Army }\end{array}$ \\
\hline 11 & $\begin{array}{l}2003 y \\
2007\end{array}$ & $\begin{array}{l}\text { Las Plazas Outlet } \\
\text { (Paseo Cancún) }\end{array}$ & $\begin{array}{l}\text { Soriana Hiper, The } \\
\text { Home Depot }\end{array}$ & 27 & 2015 & $\begin{array}{l}\text { Plaza Super Aki } \\
\text { Chac Mool }\end{array}$ & $\begin{array}{l}\text { Super Aki Gran } \\
\text { Mayoreo }\end{array}$ \\
\hline 12 & 2004 & Plaza Cobá & Chedraui & 28 & 2016 & Plaza Azuna & $\begin{array}{l}\text { Torre médica } \\
\text { y corporativa }\end{array}$ \\
\hline 13 & 2005 & $\begin{array}{l}\text { Cancún Mall (Plaza } \\
\text { las Américas 2) }\end{array}$ & $\begin{array}{l}\text { Mega Comercial Mexi- } \\
\text { cana (Soriana 2018) }\end{array}$ & 29 & 2017 & $\begin{array}{l}\text { Marina Town Cen- } \\
\text { ter Puerto Cancún }\end{array}$ & $\begin{array}{l}\text { Cinépolis, } \\
\text { Best Buy }\end{array}$ \\
\hline 14 & 2005 & Multiplaza Kabah & Bodega Aurrera & 30 & 2018 & Centralia Business Park & $\begin{array}{l}\text { Torre médica } \\
\text { y corporativa }\end{array}$ \\
\hline 15 & 2006 & Gran Plaza & Suburbia, Walmart & 31 & 2019 & Urban Center & $\begin{array}{l}\text { Best Buy, } \\
\text { Cinépolis, Fo- } \\
\text { rever } 21\end{array}$ \\
\hline 16 & 2007 & Plaza Nichupté & Soriana & & & & \\
\hline
\end{tabular}

Fuente: elaboración propia con base en estudio de campo (2019).

* En algunos inmuebles se muestra más de un año, lo cual indica las fechas de remodelación, ampliación o reinauguración.

** Las anclas corresponden a 2019. Antes de tal año, y en algunos casos, se han dado movimientos entre centros comerciales del mismo desarrollador y en otros casos han desaparecido y surgido otras nuevas.

*** En 2017 se anunció su remodelación, pero en el segundo semestre de 2019 fue vendida. Los locales interiores fueron cerrados, pero hasta la fecha sigue en funcionamiento con sus locales exteriores. 


\subsection{Distribución espacial de los centros comerciales de Cancún}

Con la finalidad de tener una mayor comprensión sobre la distribución de los centros comerciales y su incidencia en la estructura urbana de Cancún, se elaboró una zonificación que divide la totalidad del área urbana de Cancún en cuatro zonas, las cuales se representan en la Figura 1.

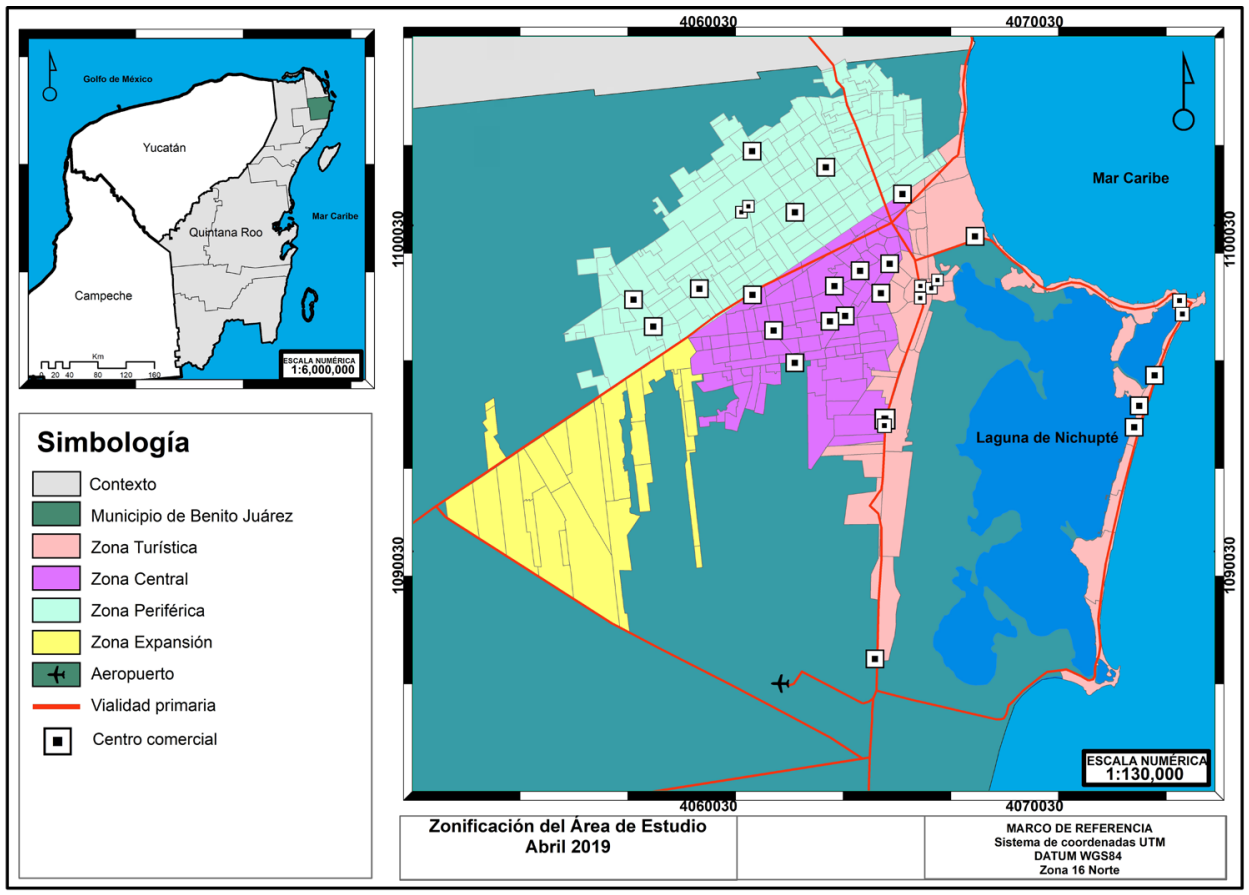

Figura 1. Zonificación del área de estudio

Fuente: elaboración propia con base en Inegi $(2010,2018)$ y estudio de campo (2019).

El área rosada corresponde a la zona turística $(\mathrm{ZT})$ que, de acuerdo con las variables utilizadas de Inegi (2010), representaría a los sectores socioeconómicos altos, con aproximadamente $77,5 \mathrm{~km}^{2}$. El área violeta corresponde a la zona central (ZC), que representa los sectores socioeconómicos medios, con aproximadamente $30,8 \mathrm{~km}^{2}$. El área azul turquesa corresponde a la zona periférica (ZP), que representa los sectores socioeconómicos bajos, con aproximadamente $38,7 \mathrm{~km}^{2}$. El área amarilla corresponde a la zona en expansión (ZE) que se encuentra ocupada por pequeños y dispersos núcleos de asentamientos irregulares; no obstante, desde 2016 comenzó la lotificación de predios sin servicios a muy bajo costo y cuenta con aproximadamente $42,5 \mathrm{~km}^{2}$.

Tomando en cuenta la distribución general de los centros comerciales para cada una de las zonas, es decir, considerando solo la ubicación de los inmuebles sin tomar en cuenta las características distintivas, como anclaje y tipos, entre otras, se 
tiene que en la zona turística existen trece centros, la zona central cuenta con diez de ellos y la zona periférica tiene ocho centros comerciales. En los siguientes apartados se desarrollan las distribuciones por décadas, por sexenios presidenciales, por tipo de anclaje, por tipo de área de influencia y por tamaño de superficie. Con lo anterior, clarifica la segregación espacial dada con la construcción de estas edificaciones comerciales.

\subsection{Distribución por décadas}

La primera distribución espacial se caracteriza por su forma temporal, esto a partir de la inauguración del primer centro comercial hasta el último inaugurado. Lo anterior conforma cuatro décadas que van de 1979 a 2019. En la Figura 2 se hacen evidentes los orígenes de la segregación espacial, puesto que desde la primera década (1979-1989) se dio preferencia a la zona turística con el $70 \%$ de los centros comerciales construidos y solo el $30 \%$ está en la ZC. En la segunda década (1989-1999) se mantuvo la situación y se presentaron los mismos porcentajes, pero con el doble de inmuebles construidos respecto a la década anterior. Evidentemente, a principios de la década de los noventa, cuando el modelo neoliberal es el orientador del mercado inmobiliario en Cancún, este era uno de los pocos lugares del país donde se invertía, se generaban empleos y se obtenían ganancias, esenciales por la crisis económica de la época. En la tercera década (1999-2009) comenzaron a surgir centros comerciales en la zona periférica, de esta forma los porcentajes fueron del $10 \%$ en la ZT, $30 \%$ en la ZP y $60 \%$ en la ZC.

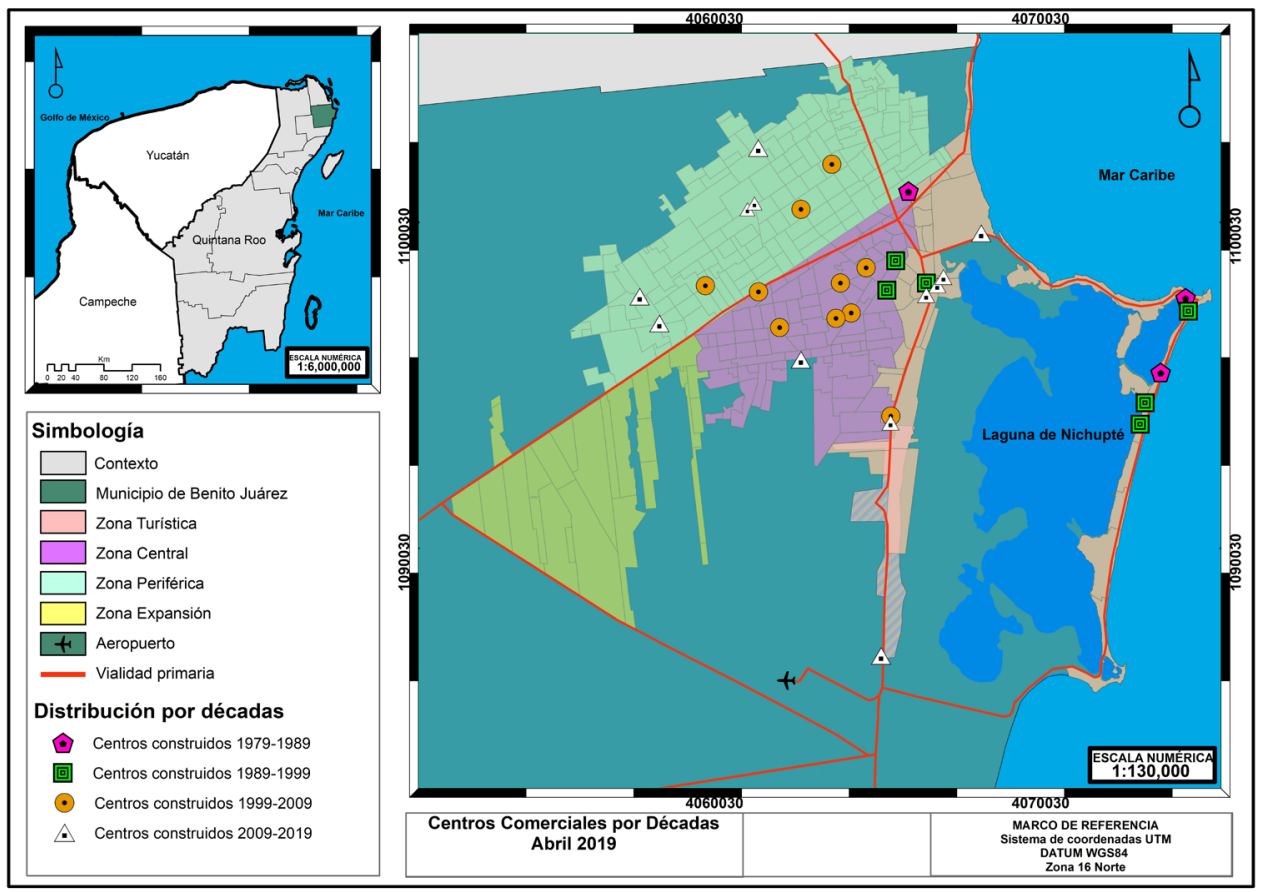

Figura 2. Centros comerciales por décadas

Fuente: elaboración propia con base en estudio de campo (2019) e Inegi (2010, 2018). 
Pareciera ser que aquí se dejaba el patrón segregador, sin embargo, solo ocurrió un desplazamiento por la preferencia espacial de la zona turística a la zona central, donde esta última tomaba el papel central, segregando a la naciente zona periférica que ya impulsaba el crecimiento de los asentamientos más populares de Cancún. Esto, hipotéticamente, está relacionado con la expansión urbana que dirigía el crecimiento demográfico hacia esa zona. En ese momento el Gran Caribe crecía y ciudades como Playa del Carmen o la isla de Cuba se incluían en la lista de los inversionistas españoles (Sosa \& Cazal, 2015). En la presente década (2009-2019) las tres zonas inauguraron centros comerciales, no obstante, regresó la preferencia espacial para los sectores socioeconómicos más acomodados: el mayor porcentaje se dio en la zona turística, con el $50 \%$, seguida muy de cerca por la zona periférica, con el $42 \%$, y solo un centro comercial (8\%) para la zona central. La distribución de centros comerciales en el último periodo es visible sobre avenidas principales que conectan la zona turística (ZT) y, a su vez, con el aeropuerto, que representan simbólicamente el desarrollo Cancún ante la vista de los turistas.

\subsection{Distribución por sexenios presidenciales}

Con la perspectiva de esta distribución se encontró que en los sexenios de López Portillo y De la Madrid se construyó solo un centro comercial por cada periodo, el primero en la zona turística y el segundo en la zona central. En el siguiente sexenio, Salinas de Gortari solo construyó dos centros en la zona turística (Figura 3).

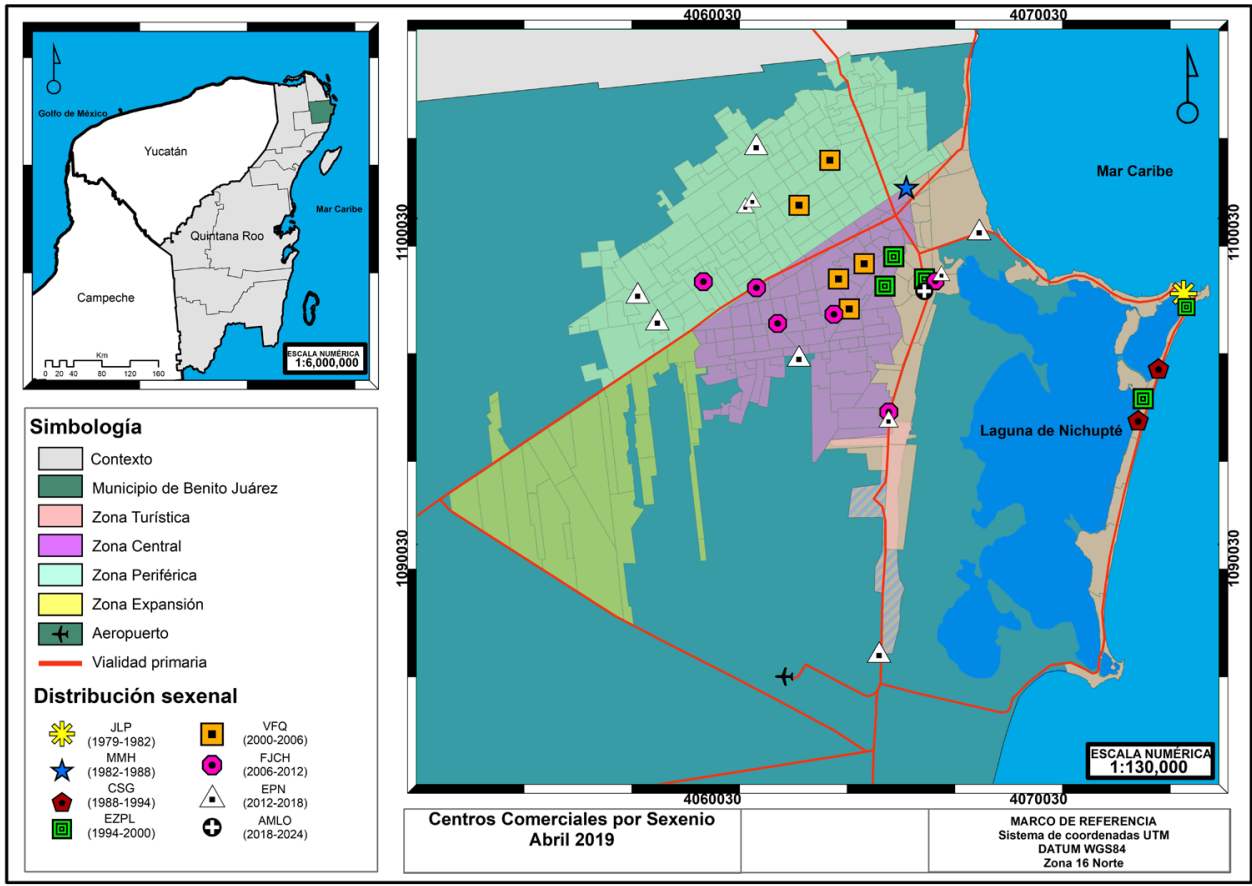

Figura 3. Centros comerciales por sexenios presidenciales 
Cabe destacar que en esta época comenzó la descontrolada expansión de la mancha urbana periférica debido a la modificación constitucional que facilitaba la incorporación de suelo ejidal a suelo urbano, razón por la cual los ejidatarios prefirieron vender sus parcelas antes de ser sorprendidos con una expropiación (Calderón \& Orozco, 2009). Para el último gobierno federal del siglo pasado, gestionado por Ernesto Zedillo, la preferencia espacial se dio, al igual que con los anteriores presidentes, en la zona turística, con cinco centros que se incorporaron a la traza urbana de Cancún; el $60 \%$ de ellos se instaló en la ZT y el $40 \%$ en la ZC. Cabe destacar que a pesar de la crisis financiera heredada por el anterior sexenio de Salinas de Gortari, Zedillo construyó más del doble que su antecesor y el quíntuple respecto a López Portillo y De la Madrid.

En cuanto a los gobiernos que comenzaron con este nuevo milenio se halló lo siguiente: Vicente Fox rompió el patrón sexenal al dejar de atender la ZT, concentrándose en la ZC con el $60 \%$ de centros comerciales y construir el $40 \%$ en la ZP, zona que por primera vez albergaría centros comerciales anclados por tiendas de autoservicio. Consecuentemente, el sexenio de Calderón fue el primero en construir centros en las tres zonas, con preferencia por la ZC al inaugurar el $50 \%$ de sus centros comerciales, $30 \%$ en la ZT y $20 \%$ en la ZP. El mandato de Peña Nieto dio preferencia espacial a la ZT y la ZP, ambas cercanas al $45 \%$, y solo el $10 \%$ en la ZC. Resulta paradójico que durante los gobiernos de Fox y Calderón, de ultraderecha y con políticas neoliberales y comerciales más intensas, se esperaba que construyeran más centros comerciales; sin embargo, la competencia en el Caribe mexicano y la creciente Riviera Maya influyeron para dirigir las inversiones hacia la construcción de hoteles. Algunas autoras, como Sosa y Cazal (2015), señalan que también se presentaron errores que pudieron intervenir en la disminución de centros comerciales, como los problemas de contaminación, destrucción de dunas y el impacto en la laguna Nichupté. Se destaca que el hallazgo más sorprendente se dio en el sexenio de Peña Nieto al inaugurar diez inmuebles, la mayor cantidad de centros en toda la historia comercial de Quintana Roo, detonando con ello la proliferación de este tipo de edificaciones en Cancún.

Al cierre de la investigación, López Obrador ha regido quince meses de gobierno con un centro registrado en la $\mathrm{ZT}$, aunque la construcción de dicho inmueble se gestó en la administración de Peña Nieto con la intención de inaugurarlo en 2018 (Rodríguez, 2017) pero se postergó hasta el primer semestre de 2019 (Sánchez, 2019). La incertidumbre empresarial causada por el nuevo gobierno de izquierda provocó que las tiendas de Urban Center abrieran de forma paulatina; tal es el caso que sus anclas más atractivas se instalaron a finales del mismo año (Ricalde, 2019). Queda pendiente analizar el sexenio presidencial de López Obrador, quien ha pregonado el fin del neoliberalismo en México, por tanto, será necesario verificar si las políticas urbanas de exclusión y segregación dejan de incidir en el territorio o lo fragmentan aún más. Por lo pronto, tiene a favor la ralentización de nuevos centros en el primer año de gobierno, no obstante aún restan cinco años por recorrer.

\subsection{Distribución por tipo de anclaje}

En la distribución por tipo de anclaje o tiendas ancla se tiene que en todo el territorio de Cancún existen tres centros comerciales anclados por tiendas departamentales, es decir, el 10\% del to- 
tal; en cuanto a los centros anclados por tiendas de cadena, sean cines, restaurantes o discotecas, se contabilizaron ocho, es decir, el $25 \%$ del total de los centros cancunenses. Cabe anotar que la mayor cantidad de centros comerciales en Cancún son anclados por tiendas de autoservicio, dado que son 20 inmuebles insertados en la estructura urbana y cubren el $65 \%$ del total de los centros construidos en Cancún.

La segregación espacial se descubre de nueva cuenta al observar que la zona turística (ZT) contiene el $100 \%$ de los centros comerciales anclados por tiendas departamentales y también el 100\% de los centros anclados por tiendas de cadena, cines, restaurantes y discotecas, que abandonan drásticamente la ZC y la ZP dejándolas sin acceso a los tradicionales malls, lo cual reduce sus opciones de entretenimiento y ocio. En cuanto a los centros anclados por tiendas de autoservicio, se develó que el $50 \%$ se localizan en la zona central (ZC), el $40 \%$ en la zona periférica (ZP) y solo el $10 \%$ en la zona turística (Figura 4). Aunque pareciera que existe una distribución más equilibrada, se sigue manteniendo la preferencia espacial para la ZC y la ZT, ya que la suma de los porcentajes indica una inclinación hacia las zonas medias y altas, con el 60\%.

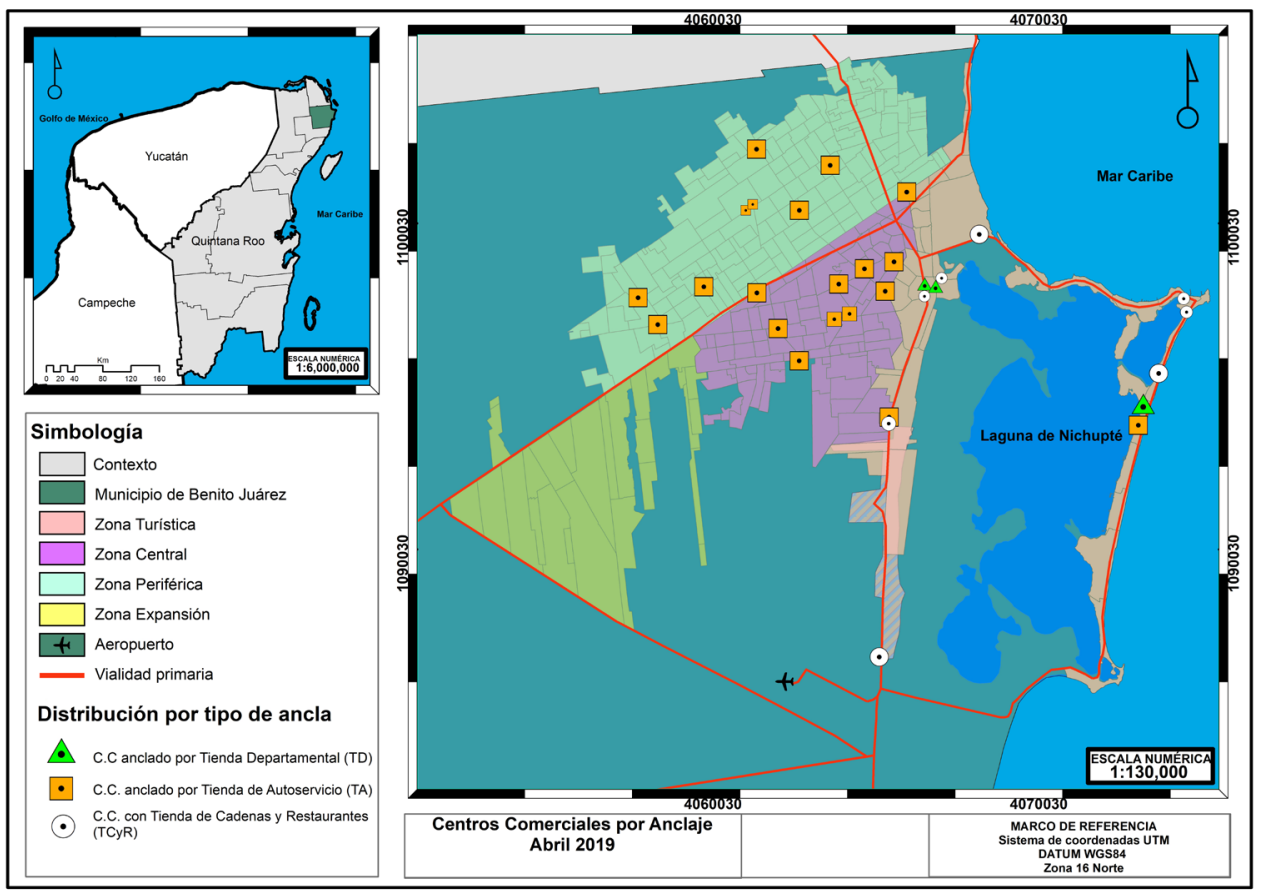

Figura 4. Centros comerciales por tipo de anclaje

Fuente: elaboración propia con base en estudio de campo (2019) e Inegi (2010, 2018). 


\subsection{Distribución por tamaño de superficie}

Respecto a los centros comerciales según su tama$\tilde{\text { ño }}{ }^{13}$, se tiene que la mayor cantidad de los inmuebles son medianos (ME), seguidos por ocho chicos $(\mathrm{CH})$ y ocho grandes (GR); en la clasificación muy grande (MG) solo existen cinco centros. Al enfocarnos en la distribución por zonas se tiene que la ZT alberga el $60 \%$ de los centros muy grandes y el $63 \%$ de los centros chicos; la ZC tiene cuatro de los ocho centros grandes, es decir, el 50\% (Figura 5). Se confirma la segregación constante para la zona periférica (ZP), que contiene el $40 \%$ de los centros

13 Partiendo de la metodología de ICSC (2018), el tamaño chico (CH) se establece de 5.000 a 19.999 m2; mediano (ME), de 20.000 a 39.999 m2; grande (GR), de 40.000 a 79.999 m2; y muy grande (MG), de 80.000 m2 o más. medianos y la cantidad mínima de los otros tamaños. Parece paradójico que los centros comerciales más chicos se encuentran en su mayoría en la zona turística, con un $63 \%$; sin embargo, son los centros comerciales más exclusivos, con las tiendas más reconocidas y con mayor oferta comercial.

Ante lo anterior, se destaca que el tamaño de los centros comerciales se relaciona con la tipología comercial, ya que son centros pequeños, pero con tiendas de alto impacto, lo cual cambiaría su connotación por ser inmuebles comerciales que se dirigen a un público exclusivo que en su mayoría no reside en Cancún. Cabe anotar que aquí surge un potencial tema de análisis para la geografía del turismo que contemple los diferentes usos del espacio por parte de la población cosmopolita vacacionista y los residentes de la ciudad.

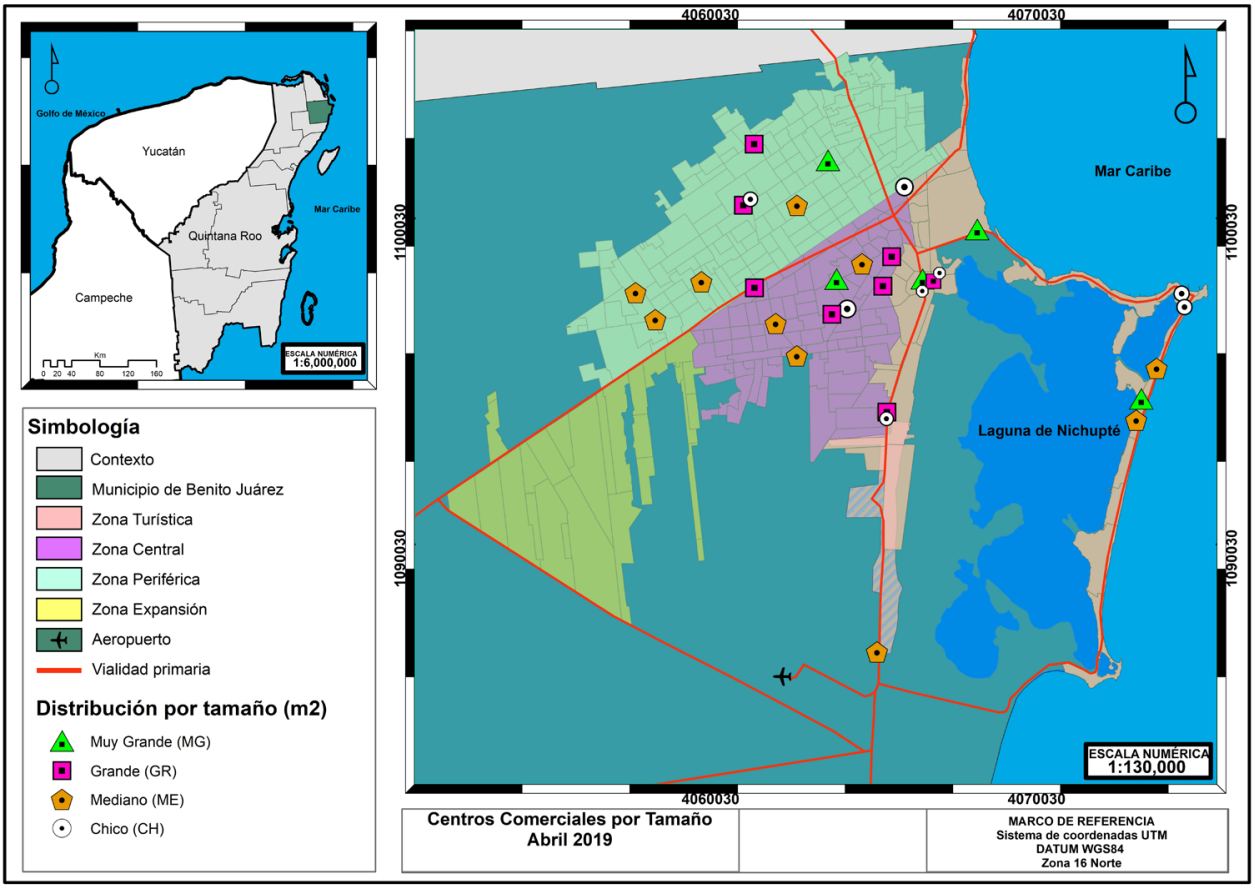

Figura 5. Centros comerciales por tamaño de superficie 


\subsection{Distribución por tipo de área de influencia}

Las áreas de influencia ${ }^{14}$ mantienen una fuerte relación con el anclaje y el tamaño a partir del tipo de tiendas y la cantidad disponible en la superficie construida. En la traza urbana de la ciudad, poco más de la mitad de los centros son de influencia de conveniencia (52\%), seguidos por seis cen-

\footnotetext{
14 Según la ICSC (2018), el área de influencia por conveniencia (Con) se corresponde con centros que albergan de una a 50 tiendas; de vecindario (Vec), entre 51 y 100; comunitario (CM), de 101 a 150; y el área de influencia regional (RG alberga 151 o más.
}

tros de influencia de vecindario (19\%), cinco de influencia comunitaria $(16 \%)$ y finalmente solo existen cuatro inmuebles comerciales de influencia regional, los cuales significan el 13\% del total. Aplicando el filtro de la zonificación elaborado, se encontró que en la zona periférica (ZP) existe un centro de influencia comunitaria, dos vecinales y cinco de conveniencia. En la zona central (ZC) se detectó el $40 \%$ de los centros comunitarios (CM) y el $44 \%$ de los centros de conveniencia (Con). La zona turística (ZT) contiene el 100\% de los centros comerciales de influencia regional, la modalidad con mayor atracción poblacional (Figura 6).

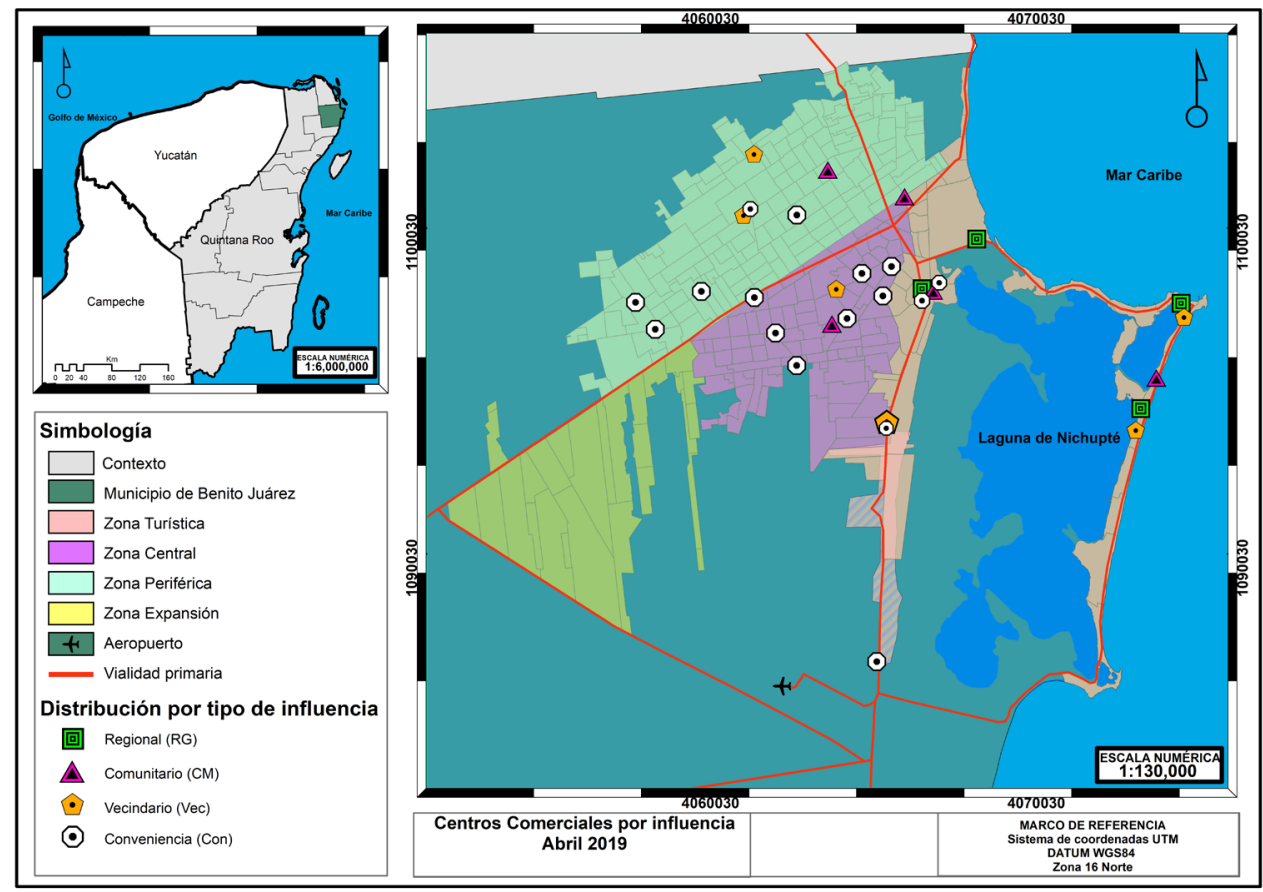

Figura 6. Centros comerciales por tipo de área de influencia

Fuente: elaboración propia con base en estudio de campo (2019) e Inegi (2010, 2018). 
Aunque esta distribución pareciese más equitativa, la segregación sigue existiendo si se analiza que la ZT tiene centros de todo tipo de influencia, que ofrecen mayor diversidad y oferta comercial para los habitantes que la conforman. Los beneficios socioespaciales cambian cuando se trata de sectores socioeconómicos más adinerados: en anteriores distribuciones, la ZT y la ZC resaltaron por encima de la ZP, sin embargo, aquí se reafirma cuál es la zona que constantemente ha recibido preferencia espacial, y no ha sido casualidad entonces haber construido Plaza Caracol en el corazón de la zona turística.

\section{Conclusiones}

El análisis de las distribuciones espaciales permitió verificar que los centros comerciales de Cancún han colaborado con la agudización de su ya característico territorio segregado. El descuido de la ciudad y la carencia de planeación urbana fue evidente cuando el Estado dejó el control del proyecto Cancún, apostando a la inversión privada con un modelo encaminado a crear una ciudad turística exclusiva. A lo largo de cuarenta años se presentaron siete sexenios presidenciales que otorgaron facilidades espaciales al desarrollo de zonas socioeconómicas medias y altas, como parte de una política pública de empuje al turismo internacional que deja una enorme derrama económica. Esto ha segregado las zonas de vivienda de los trabajadores que llegan ofreciendo su mano de obra para construcción, comercio o servicios, y que también requieren lugares de consumo y ocio. La consecuencia de las políticas neoliberales impuestas durante diferentes gobiernos federales fue la constitución de una ciudad enfocada en usos del suelo que satisfacen las necesidades de unos cuan- tos y deterioran la calidad de vida de los lugareños. Lo anterior por dos razones principales: la primera es el esquema neoliberal que abre las puertas a inversiones que generan empleos; sin embargo, las responsabilidades empresariales se diluyen en la permisividad eliminando accesos a vivienda, servicios de salud y otros. En segundo lugar, quien ofrece su mano de obra busca opciones diversas y accesibles para obtener vivienda, empleo y servicios. Se sigue construyendo un Cancún segregado social y espacialmente, que sigue en auge de expansión sin un desarrollo urbano incluyente.

Los resultados de la investigación indican que desde el año 2000 estas construcciones comerciales se han incrementado en la ciudad, y con mayor frecuencia en la última década. El encuadre de tres diferentes zonas de la ciudad posibilitó comprobar una estructura urbana caracterizada por ubicaciones selectivas y ajustadas a las áreas con mayor calidad de vida destinadas para la población flotante que visita la zona turística, situación que, a la postre, ha terminado fragmentando la ciudad, trazando vías y núcleos segregadores reforzados por centros comerciales. Por medio de la zonificación se logró constatar el patrón de beneficios espaciales para la zona turística, que abarca los mayores porcentajes en todas las distribuciones y el 100\% del anclaje departamental, cadenas y restaurantes. La división marginal de los centros se estructura por una mayor cantidad distribuida en zonas medias y altas, con centros que mejoran la calidad comercial de tiendas ancla, con superficies más amplias y centros más chicos, pero más exclusivos. Con la génesis de los centros en Cancún se constató que la zona central, y posteriormente la zona periférica, fueron áreas segregadas que con el tiempo fueron acrecentándose y desplazándose conforme avanzaba la penetración del neoliberalismo, configurando 
así fragmentos territoriales que solo satisfacen las necesidades comerciales de usuarios temporales, ya que se ubican los mejores centros en lugares exclusivos y ajustados para la población flotante que visita la zona turística y para los ciudadanos que habitan las áreas con mayor calidad de vida.

A partir del estudio realizado es posible argumentar que actualmente la estructura urbana de Cancún está desarticulada y que las diferencias entre las zonas turística, central y periférica producen una expansión urbana difusa y confusa. Aquí la población realiza su vida cotidiana entre la opu- lencia, la escasez y la mezquindad, viviendo tres tipos de ciudad en una misma; los entornos lujosos de lugares laborales en la zona turística se contraponen con lugares de vivienda en la zona central y más aún en la zona periférica que habitan los trabajadores con menos recursos económicos. Queda claro entonces que los centros comerciales de Cancún han aportado trazos y pinceladas de segregaciones dibujadas en la distribución espacial, lo cual fomenta la desintegración social y afecta a la población más vulnerable. 


\section{Referencias}

Ayuntamiento de Benito Juárez (2018). Plan Municipal de Desarrollo del Municipio de Benito Juárez, Quintana Roo (2018-2021). Recuperado de https://cancun.gob.mx/ archivos_pdf/Planmunicipal/Plan_Municipal_de_Desarrollo_20182021.pdf.

Calderón, J. \& Orozco, M. (2009). Planeación y modelo urbano: el caso de Cancún, Quintana Roo. Quivera, 11(2), 18-34.

Cárdenas, E. (2016). Crecimiento y planeación urbana en Acapulco, Cancún y Puerto Vallarta. Revista Investigaciones Turísticas, 12, 99-120. doi: http://dx.doi. org/10.14198/INTURI2016.12.05.

Castillo, O. (2011). Segregación socioespacial en Cancún: 1990-2010 tres ciudades en una misma. Provincia, 26, 11-31.

Consejo Nacional de Población (Conapo). (2012). Catálogo. Sistema Urbano Nacional 2012. México: Conapo.

Cornejo Portugal, I. (2006). El centro comercial: ¿una nueva forma de "estar juntos"? Cultura y Representaciones Sociales, 1(1), 93-127. Recuperado de http://www.scielo. org.mx/scielo.php?script=sci_arttext\&pid=S2007-81102006000100004\&lng=es \&tIng=es.

Daltabuit, G. M., Cisneros, H., Vázquez, L. \& Ruiz, G. (2006). Turismo costero en la ecorregión del sistema arrecifal mesoamericano. México: Centro Regional de Investigaciones Multidisciplinarias (CRIM), UNAM.

Gasca-Zamora, J. (2017). Centros comerciales de la Ciudad de México: el ascenso de los negocios inmobiliarios orientados al consumo, EURE, 43(130), 73-96.

García, E. (25 de febrero de 2016). La nueva era de los centros comerciales. Inmobiliare. Recuperado de https://inmobiliare.com/la-nueva-era-de-los-centroscomerciales/.

Instituto de Planeación de Desarrollo Urbano (Implan, BJ). (2008). Plan Estratégico Cancún 2030, Implan, Cancún, Municipio de Benito Juárez, Quintana Roo. Recuperado de http://implancancun.gob.mx/programas/.

Instituto Nacional de Estadística y Geografía (Inegi). (1980). Censo de Población y Vivienda 1980. Recuperado de https://www.inegi.org.mx/programas/ccpv/1980/.

Instituto Nacional de Estadística y Geografía (Inegi). (1990). Censo de Población y Vivienda 1990. Recuperado de https://www.inegi.org.mx/programas/ccpv/1990/. Instituto Nacional de Estadística y Geografía (Inegi). (2000). Censo de Población y Vivienda 2000. Recuperado de https://www.inegi.org.mx/programas/ccpv/2000/. Instituto Nacional de Estadística y Geografía (Inegi). (2010). Censo de Población y Vivienda 2010. Recuperado de https://www.inegi.org.mx/programas/ccpv/2010/.

Instituto Nacional de Estadística y Geografía (Inegi). (2015). Encuesta Intercensal 2015. Recuperado de https://www.inegi.org.mx/programas/intercensal/2015/. 
Instituto Nacional de Estadística y Geografía (Inegi). (2018). Marco Geoestadístico Nacional 2018. Recuperado de https://www.inegi.org.mx/app/biblioteca/ficha. html?upc=889463592587.

International Council of Shopping Centers (ICSC). (2016). Estudios especiales. Recuperado de https://www.icsc.com/uploads/event_documents/ICSC_ Programa_Seminario_de_Gesti\%c3\%b3n_de_CC_y_Retail_13_Octubre, Rep\%c3\%bablica_Dominicana.pdf.

López, L. (1999). Centros comerciales, espacios que navegan entre la realidad y la ficción. México: Nuestro Tiempo.

López, L. (2006). Centros comerciales, recintos fortificados. Veredas, 7(12), 147-163.

Lulle, T. y Paquette, C. (2007). Los grandes centros comerciales y la planificación urbana. Un análisis comparativo de dos metrópolis latinoamericanas, Estudios Demográficos y Urbanos, 22(2), 337-361.

Medina, F. (1998). El centro comercial: una "burbuja de cristal". Estudios sobre las Culturas Contemporáneas, 4(8), 61-91.

Müller, J. (1998). Grandes centros comerciales y recreacionales en Santafé de Bogotá. Origen, características y tendencias de desarrollo. Perspectiva Geográfica, 3, 48-87.

Olguín, C. (2011). Retail apuesta por expansión en el 2011. Real Estate Market \& Lifestyle. Recuperado de http://www.realestatemarket.com.mx/articulos/ mercadoinmobiliario/comercial/11413-retail-apuesta-por-expansion-en-2011.

Pérez, G. \& Carrascal, E. (2000). El desarrollo turístico en Cancún, Quintana Roo y sus consecuencias sobre la cubierta vegetal. Investigaciones Geográficas, 43, 145-166.

Pradilla, E. (2017). Zona Metropolitana del Valle de México: Cambios socioterritoriales, México, D. F.: Universidad Autónoma Metropolitana.

Pradilla, E. \& Pino, R. (2004). Ciudad de México: de la centralidad a la red de corredores urbanos. En Anuario de Espacios Urbanos, Historia, Cultura y Diseño 2004 (pp. 71-96). México, D. F: Universidad Autónoma Metropolitana.

Programa de Desarrollo Urbano del Centro de Población Cancún, Municipio Benito Juárez, Quintana Roo (2014-2030). Recuperado de http://seduvi.qroo.gob.mx/ pdus/36-PDU\%20DEL\%20CENTRO\%20DE\%2OPOBLACION\%20CANCUN\%20 BENITO\%20JUAREZ\%20QUINTANA\%20ROO\%202014-2030(1).pdf.

Ramírez, B. \& Pradilla, E. (Comps.), (2014). Teorías sobre la ciudad en América Latina. México: UAM-Xochimilco, CyAD, Edit. Ink.

Ramírez Kuri, P. (1993). Transformaciones espaciales y modernización urbana: la ciudad de México y los macro-proyectos comerciales. Centro Comercial Coyoacán (1989-1993). (Tesis de maestría en Estudios Regionales). Instituto de Investigaciones Dr. José María Luis Mora, México.

Ramírez Kuri, P. (1998). Coyoacán y los escenarios de la modernidad. En N. García Canclini (coord.), Cultura y comunicación en la ciudad de México. Primera parte. Modernidad y multiculturalidad: la ciudad de México a fin de siglo (pp. 321-367). México: Grijalbo/UAM-Iztapalapa. 
Ricalde, J. (14 de septiembre de 2019). Así será la nueva plaza comercial del centro de Cancún. Revista Be! Recuperado de https://www.revistabe.com.mx/2019/09/asisera-la-nueva-plaza-comercial-del.html.

Rodríguez, F. (7 de junio de 2017). México: preparan dos nuevos centros comerciales en Cancún. Fashion Network. Recuperado de https://pe.fashionnetwork.com/ news/Mexico-preparan-dos-nuevos-centros-comerciales-en-cancun,835133. html.

Salcedo-Hansen, R. (2003). Lo local, lo global y el mall: la lógica de la exclusión y la interdependencia. Revista de Geografía Norte Grande, 30, 103-115.

Sánchez, M. (30 de octubre de 2019). Plaza Urban abrirá este año. Radio Fórmula QR. Recuperado de https://radioformulaqr.com/noticias/quintana-roo/cancun/plazaurban-abrira-este-ano/.

Sosa, A. y Cazal, A. (2015). El espacio público en la Ciudad de Cancún frente al proyecto turístico. URBS. Revista de Estudios Urbanos y Ciencias Sociales, 5(2), 65-80.

Treviño, F. (19 de junio de 2017). El 'boom' de las plazas comerciales en México. El Diario de Coahuila. Recuperado de http://www.eldiariodecoahuila.com.mx/.

UBM se convierte en Informa Markets Latam a siete años de su surgimiento. México Extraordinario. Recuperado de http://mexicoextraordinario.mx/ubm-se-convierteen-informa-markets-latam-a-siete-anos-de-su-surgimiento/.

Vázquez, Y. (2000). Los centros comerciales en la ciudad de México. (Tesis de maestría en Desarrollo Urbano). México, Centro de Estudios Demográficos y de Desarrollo Urbano, El Colegio de México. 